\title{
LIDERANÇA NAS ORGANIZAÇÕES
}

Everton Luiz Yamafuko'; Jerson Joaquim Silva²

Universidade do Oeste Paulista - UNOESTE, Curso de Administração, Presidente Prudente, SP. E-mail: jsilva@unoeste.br

\section{RESUMO}

As organizações estão, cada vez mais, buscando colaboradores capacitados para terem, a partir deste capital humano, um diferencial no mercado e é o líder que tem a responsabilidade de fazer com que o colaborador sinta a necessidade de fazer o melhor para a empresa e também se sentir motivado e satisfeito dentro dela. O líder deve sempre estar ao lado de sua equipe, conhecendo cada um de seus liderados, aconselhando-os nas tomadas de decisões e nos relacionamentos entre si, sempre em busca dos objetivos propostos. Para contemplar este trabalho fez-se uso da pesquisa bibliográfica, exploratória e descritiva e teve como objetivo averiguar o papel do líder na motivação de uma equipe de trabalho.

Palavras-chave: Organizações; Colaboradores; Capital Humano; Líder; Equipe.

\section{LEADERSHIP IN ORGANIZATIONS}

\begin{abstract}
Organizations are increasingly seeking qualified employees to have, from this human capital , a differential in the market and is the leader who has the responsibility to make the employee feel the need to do the best for the company and also feel motivated and satisfied in her. The leader must always be beside his team , knowing each of their team members, advising them in decision making and relationships with each other, always in search of goals.

Keywords: Organizations; Contributors; Human capital; Leader ; Team.
\end{abstract}




\section{INTRODUÇÃO}

Cada vez mais o mercado se encontra competitivo e, por esses fatores o papel do líder também tem passado por diversas mudanças significativas, pois o líder de antigamente tinha um perfil mais autoritário e se posicionava sempre à frente de sua equipe, o que o deixava mais distante de seus liderados.

Porém, o papel do líder, atualmente, é completamente diferente, as organizações estão buscando cada vez mais capacitar seu capital humano, já que não basta apenas ter maquinários se não possuir colaboradores capacitados e motivados, e é por isso que o líder se tornou a peça chave para esse processo, buscando em cada membro de sua equipe o melhor, tanto para a empresa quanto para o próprio colaborador.

Nos dias de hoje, o líder se coloca ao lado de sua equipe apoiando e incentivando, fazendo com que a própria equipe faça acontecer, para isso, é fundamental que conheça o perfil de cada integrante que a compõe, pois uma organização nasce de um sonho, e cada integrante também possui seus sonhos particulares.

É nesse sentido que este trabalho se justifica, pois visou desvendar as condições que o líder pode proporcionar para que seus liderados se mantenham motivados, influenciando-os no sentido de ter um melhor relacionamento a fim de atingir as metas propostas pela organização.

Para tanto, elencou-se o objetivo geral averiguar o estilo de liderança mais adequado para gerir uma equipe de trabalho.

\section{METODOLOGIA}

O presente trabalho utilizou-se da seguinte abordagem:

- Qualitativa -pois há um vínculo indissociável entre o mundo objetivo e a subjetividade do sujeito que não pode ser traduzido em números.

- Pesquisa bibliográfica- visto que abrangeu bibliografia já tornada pública em relação ao tema de estudo, desde publicações avulsas, boletins, jornais, revistas, livros, pesquisas, monografias, teses, material cartográfico etc [...]".

Portanto, esse estudo foi de forma bibliográfica, qualitativa e descritiva, pois os pesquisadores pesquisaram a respeito do tema proposto em revistas, livros, artigos, dissertações, monografias e outros meios científicos de escritas científicos que se apresentarem presentes e convenientes, para então após embasamento comprovado e confiável, apresentarem suas próprias teorias sobre o tema e conclusões sobre as problemáticas apresentadas. Ao final deste 
estudo, buscaram-se soluções satisfatórias e que possam realmente ajudar e trazer benefícios aos interessados pelo assunto proposto.

\section{Liderança de antigamente e dos dias atuais}

Liderança, ao contrário do que muitos pensam, não se aplica apenas dentro das organizações, pode existir liderança em qualquer meio em que os indivíduos se encontram: lideranças de bairro, de comunidades, de voluntários, enfim, onde houver um grupo de pessoas que possuírem um objetivo em comum, sempre haverá de se sobressair entre elas um indivíduo que os conduzirá, e os orientará para o alcance de seus objetivos.

Nos dias atuais, a necessidade de liderar equipes passou a ser de extrema importância a fim de criar vínculo que aproxime e dê incentivo ao colaborador, proporcionando alto comprometimento com o exigido pela organização, podendo gerar satisfação para ambas as partes envolvidas.

Nesse sentido, pressupõe-se que as empresas estão cada vez mais enaltecendo a importância que um ambiente de trabalho saudável para que seus colaboradores alcancem os objetivos e metas estipuladas pela organização, e também seus objetivos pessoais, criando vantagem para concluírem bons negócios.

De acordo com Chiavenato $(2010$, p.8). "todo processo produtivo somente se realiza com a participação conjunta de diversos parceiros, cada qual contribuindo com algum recurso."

Pressupõe-se que o profissional deve estar motivado para colaborar com a organização, ou seja, potencializando seus conhecimentos, suas habilidades e capacidades aliadas com a motivação e a adequação do processo, podendo reduzir a probabilidade de erros.

Para que se possa ter um sucesso profissional, que abranja conhecimento, reconhecimento, alegria, satisfação e claro o dinheiro, precisa-se ter o conhecimento de como fazer o grupo andar sem tropeços. Com isso, percebe-se a importância de um líder para o seu grupo. Nesse sentido, entende-se que todo administrador deve ser um líder em algum nível da administração e o papel de gerir requer habilidades de liderança e administração. O gestor, ao exercer a liderança, enfrenta desafios diários e vive numa luta constante para superar as dificuldades e manter o ânimo forte.

Sobre isso, Drucker (1996, p.1), considerado o pai da administração moderna, afirma que “(...) o líder tem que gerenciar a si próprio; conhecer as suas forças e colocá-las em benefício dos bons propósitos. A liderança começa, não quando você estabelece regras para os outros, mas quando você traça regra muito exigente para si próprio". Entende-se, pela fala do autor, que para 
se tornar um bom líder, primeiramente, deve-se policiar diante das atitudes, onde o líder é um espelho para seus subordinados e é dele que se deve vir o exemplo.

Supõe-se que, para obter uma boa liderança, o líder precisa possuir várias virtudes entre elas: autoconfiança, autoconhecimento, humildade, motivação, ética, empatia, entusiasmo e inteligência acima da média.

Antigamente, a definição de liderança se baseava na genética, em que se falava que era algo que se herdava de alguém de sua família, porém, devido às mudanças que o mundo sofreu, essa teoria veio abaixo, pois ocorreram casos de pessoas, dentre elas homens e mulheres, que conseguiram alcançar uma posição de liderança, sem mesmo pertencerem à realeza, fato que não havia como se explicar.

Por isso, buscar compreender a liderança na sua forma sentimental não acaba explicando seu motivo de existência. O que de fato entende-se é que o líder é líder não por possuir características, não fornecendo um padrão básico para os líderes, mas sim por possuir os traços ideais aos seus seguidores, à determinada situação, sendo singular a cada integrante, a equipe e a situação enfrentada. Desse modo, não pode afirmar que um líder já nasce líder, esse dom de influenciar pessoas não vem, como se imaginava realmente, do berço. Na realidade, não há como definir modelo para o líder, suas características surgem conforme o ambiente em que ele trabalha.

Segundo Burns, $(1978$, p.20):

Liderança é um processo no qual líderes e seguidores elevam um ao outro a níveis mais altos de moralidade e motivação, aumentando o grau de conscientização dos seguidores fazendo uso de elevados ideais e valores morais, como liberdade, justiça, igualdade, paz e humanitarismo, e não através de emoções mesquinhas, como medo, ganância, ciúmes e ódio.

Desse modo, entende-se que a influência na qual o líder proporcionará sobre sua equipe, somente será possível através do conhecimento das características individuais, as potencialidades de cada integrante, pois dessa forma, possibilita a ele buscar os melhores resultados que a organização pretende.

Sendo assim, pode-se perceber o porquê de a figura do líder estar sendo tão procurada e valorizada pelas empresas, pois ele possui a habilidade de desenvolver seus colaboradores trabalhando no que eles têm de melhor, verificando e contribuindo para as potencialidades de cada um e também aprende com isso. Essa sinergia se torna importante, pois à medida que os colaboradores se desenvolvem pessoal e profissionalmente, as empresas ganham em qualidade, deixando o ambiente harmônico e producente, não excluindo a importância dos conflitos nas organizações, como elemento de mudanças, muitas vezes, necessárias. 
Afirmam Koontz e O’Donnell (apud HERSEY, 1986 p.104) que a "liderança consiste em influenciar pessoas para realização de um objetivo comum". Nota-se, num olhar mais acurado, que há uma concordância entre esses e outros estudiosos de que a liderança é "o processo de influenciar as atividades de um indivíduo ou de um grupo para a consecução de um objetivo numa dada situação" (HERSEY, 1986, p.104).

Já para Bergamini (2002, p.127), "a liderança é nitidamente um processo de influenciação que envolve, sobretudo, um ambiente de trocas contínuas entre o líder e seus seguidores". Nessa afirmação, pode-se verificar que a liderança é uma via de mão dupla que envolve as pessoas provocando certa interação.

Outro conceito, usado por Bergamini (2002, p. 7), diz que: “líder é aquele que, conseguirá fazer um grupo social consciente dos seus objetivos e valores, capaz de afirmar-se perante seus seguidores e resistir quando sua identidade for ameaçada". Assim sendo, entende-se que o líder é aquele que faz que seus liderados além de entender com clareza os objetivos, acreditem que estes são possíveis, dessa forma entregando-se com maior empenho na execução dos mesmos.

Consequentemente, ao provocar seus liderados, através da crença nos objetivos, o líder desperta a motivação em cada um, ganhando a confiabilidade de seu grupo tornando-o mais seguro no que acredita, fortalecendo sua identidade de liderança.

Supõe-se que a liderança é singular a cada indivíduo, equipe e situação enfrentada. Não há como definir um estereótipo para líderes. Essa é uma convenção de vários autores. Contudo, Bennis (1996), sugere que os líderes têm algumas características em comum, como: visão maior, paixão, Integridade e maturidade, que serão detalhadas adiante:

- Visão maior: possui habilidade de vislumbrar claramente os mecanismos e recursos necessários para se alcançar os objetivos coletivos, que sempre estão claros e límpidos para todos;

- Paixão: o líder ama o que faz e ama fazê-lo, ou seja, é comprometido e envolvido pelos seus objetivos e suas metas. Praticamente, mistura-se com seus propósitos;

- Integridade: isso significa autoconhecimento, sinceridade e maturidade. O primeiro é a capacidade de conhecer-se, de ter claras as suas capacidades e habilidades definidas, assim como, suas fraquezas e limitações. Já sinceridade, é o imperativo da idoneidade de pensamentos e ações, sem agressões aos seus princípios;

- Maturidade: implica o aspecto empírico, que é necessidade de ter percorrido os caminhos dos liderados, dos seus seguidores, ter vivas as experiências que o impulsionam para a liderança. 
Conhecendo cada integrante de sua equipe, permite ao líder trazer constantes inovações para trabalhar na melhor forma possível os procedimentos para o alcance dos objetivos, porém sempre com o foco nas pessoas, pois são nelas que o líder observa a solução dos problemas, buscando estimulá-las, ouvindo-as e desafiando-as.

De fato, o trabalho em equipe é muito relevante, mas para que tudo ocorra da melhor forma possível, é necessário dispor do reconhecimento, seja ele nas formas de alegria, satisfação e também em dinheiro, e sendo assim que se percebe a importância do líder.

Portanto, dentro do contexto do mundo globalizado, a liderança torna-se fator importante para influenciar e mobilizar pessoas dentro de uma organização, buscando assim, através de sua eficiência e agilidade, meios que garantam a sua sustentabilidade, isto é, sua sobrevivência num mundo tão competitivo.

Nesse cenário, onde as mudanças acontecem a todo momento, em que as organizações lutam para ocupar seu espaço no mercado global, o líder deve ser alguém aberto às mudanças, capaz de enxergar o futuro e, nos momentos difíceis, como diz Moscovi (1998, p.76): “O líder de verdade deve saber usar eventuais quedas para se reinventar no momento seguinte".

Atualmente, para toda e qualquer organização, o trabalho em equipe é fundamental. A palavra equipe não se aplica somente à família ou amigos, mas também a um ambiente em que passamos a maior parte do nosso tempo de vida, que é o ambiente de trabalho.

Para que se possa ter um sucesso profissional, que abranja conhecimento, reconhecimento, alegria, satisfação e claro o dinheiro, precisamos ter o conhecimento de como fazer o grupo andar sem tropeços. Com isso, percebemos a importância de um líder para o seu grupo.

Todo administrador deve ser um líder em algum nível da administração e o papel de gerir requer habilidades de liderança e administração. O gestor, ao exercer a liderança, enfrenta desafios diários e vive numa luta constante para superar as dificuldades e manter o ânimo forte.

Finalizando este capítulo, pressupõe-se que a liderança é um tema importante para os gestores devido ao papel fundamental que os líderes representam na eficácia do grupo e da organização. Liderar não é uma tarefa simples. Pelo contrário, liderança exige paciência, disciplina, humildade, respeito e compromisso. Dessa forma, pode-se defini-la como o processo de dirigir e influenciar as atividades relacionadas às tarefas dos membros de um grupo. 


\section{CONSIDERAÇÕES FINAIS}

Diversos autores tentam definir o que é ser líder, mas ainda não conseguiram uma definição única dessa questão, que, hoje em dia, vem sendo muito valorizada nas empresas. O que se pode definir é que o líder é uma pessoa que serve seus liderados, mostrando-lhes os caminhos a serem seguidos a fim de chegarem a um objetivo comum. Dessa forma, como foi estudado, o líder também deve ser admirado pelos colaboradores, pois assim, o respeito e a compreensão prevaleceram nos relacionamentos, tornando um ambiente mais agradável e com menos conflitos, alcançando os objetivos e metas estipuladas pela organização, e também seus objetivos pessoais, criando vantagem para concluírem bons negócios.

Supõe-se que cada indivíduo tenha seus objetivos próprios de vida, ou seja, cada um quer coisas diferentes do outro. Sendo assim, o líder deve se atentar a essas informações, traçando o perfil de cada colaborador para conseguir desenvolver suas habilidades potenciais e motivá-los, de tal forma, que o trabalho se desenvolva da melhor forma e qualidade possível.

Autores dizem que o colaborador espera da empresa uma série de benefícios ou recompensas para satisfazer suas necessidades e em troca ele se esforçará para realizar seu trabalho e é dessa forma que acontece no dia-a-dia das organizações, os funcionários sempre esperam algo a mais da empresa, de forma que eles sintam-se valorizados e mais motivados a desempenharem suas atividades. Está aí a importância de um líder saber mostrar o papel fundamental que o colaborador tem dentro da organização e também valorizá-lo.

Viu-se, também, que por parte do líder este deve ter uma autoestima elevada, para sentirse útil, senão, ao contrario disso, será uma pessoa frustrada e conduzida à inferioridade e, com isso, seus liderados sentiram falta de um líder mais presente e confiante nos resultados, gerando assim desconfiança por parte deles e, consequentemente, um queda no rendimento de seus serviços.

Percebeu-se a seriedade de manter esse colaborador sempre motivado, pois este espera o reconhecimento por parte da organização, assim, em troca, contribuirá com maior empenho, melhorando seu rendimento e diminuindo os erros. Nesse ponto observamos que a liderança começa quando as exigências são definidas quando o próprio líder as determina, e não quando são estabelecidas antes para sua equipe, desse modo seus pontos fortes prevalecem e os pontos fracos são ocultados.

Por meio de autores estudados, constatou-se que a maioria trata de que de fato não existe um modelo pronto para se tornar líder, mas pela razão de reterem um perfil singular para cada 
integrante de sua equipe e o local que trabalha, a questão de influenciar a todos para busca dos objetivos se tornou a principal causa de seu reconhecimento.

Porém, algumas características apontadas pelos autores sejam populares entre líderes, sendo uma delas a visão maior, que auxilia na clareza dos recursos a serem utilizados para o alcance dos objetivos, e a paixão pela realização das metas definidas, a sua integridade, ou seja, seu autoconhecimento e lealdade diante de cada situação e de todos.

Diante disso, considera-se a liderança como uma via de mão dupla, na qual antes que o produto ou serviço final sejam garantidos, é necessária uma atenção maior aos responsáveis por esse processo seja realizado da melhor forma. Com isso, constata-se que um líder é de extrema importância para uma organização, mas requer humildade e paciência, pois precisa ressaltar para sua equipe o que precisam e não o que querem.

\section{REFERÊNCIAS}

BENNIS, Warren G. A formação do Líder. Tradução: Marcelo Levy. São Paulo: Atlas, 1996.

BERGAMINI, Cecília W. O Líder Eficaz. São Paulo: Editora Atlas S.A, 2002.

BURNS, J.M. Liderança. São Paulo: Futura, 1978.

CHIAVENATO, Idalberto. Gestão de pessoas. 3. ed. Rio de Janeiro: Elsevier, 2010.

DRUCKER, Peter. O líder do futuro. São Paulo: Futura, 1996.

HERSEY, Paul. Psicologia para administradores : a teoria e as técnicas da liderança situacional. São Paulo, 1986.

MOSCOVICl, Fela. Desenvolvimento Interpessoal: Treinamento em Grupo. 8a ed. Rio de Janeiro: José Olympio, 1998. 